\title{
Interactive comment on "The influence of Atlantic climate variability on the long-term development of Mediterranean cold-water coral mounds (Alboran Sea, Melilla Mound Field)" by Robin Fentimen et al.
}

\section{Robin Fentimen et al.}

robin.fentimen@unifr.ch

Received and published: 5 September 2020

\section{Reply to Referee \#2}

Manuscript title: The influence of Atlantic climate variability on the long-term development of Mediterranean cold-water coral mounds (Alboran Sea, Melilla Mound Field)

submitted to Climate of the Past

response by: Robin Fentimen et al. 
In the following document, the responses to the comments made by Referee \#2 are addressed one by one.

General comment

Comment Referee \#2: the interpretation of the X-ray fluorescence (XRF) is a bit problematic for the production of decisive environmental interpretations, considering that the principal aim of this study is to define the climatic processes susceptible of affecting the coral mound formation. I suggest the addition of some figures and more importantly, to either tonedown some of these interpretations, or if possible, to add (or compare to) more records that support the environmental reconstructions presented in this article.

Response: We agree with Referee \#2 that interpretations linked to the XRF records need to toned down. This is also in agreement with the points raised by Reviewer \#1 (see comment and reply). Following these comments the section from Lines 581 to 602 has been deleted in the new version of the manuscript since the XRF data did not sufficiently support the interpretations made. Furthermore, we agree that down toning interpretations linked to the XRF in other parts of the manuscript is needed.

Regarding additional figures, the manuscript is already figure-rich. In addition, the comments and suggestions of Reviewer \#1 (and also Reviewer \#2, e.g. foraminiferal plates) will require the addition of extra three figures: 1 . adding the CT visualization of fragments bigger than $2 \mathrm{~cm} ; 2$. adding the Van Krevelen diagram (see reply to Referee $\# 1$; 3 . adding a plate illustrating the most important foraminifera species. As such, we consider that the manuscript will hopefully be adequately illustrated (see below for specific comments).

\section{Specific comments}

Reviewer comment: In the introduction it might widen the scope of the manuscript to add that the selected coral mound is (strategically) located at the interface between 
different water masses as showed in fig. 2.2. It is later an important aspect of the discussion.

Response: Comment integrated in the revised version of the manuscript.

Reviewer comment: The Oceanography section could be improved by describing water masses from shallower to deeper, if possible. More Calls to the figures in this section would be helpful. It would be helpful to add in fig. 2 the water masses flowing directions (crosses and dots, in and out of the paper for example). Could you please elaborate whether Alboran Sea gyres strengths and structures display seasonal changes, as you mention that they are non-permanent?

Response: Modifications made in the revised version of the manuscript. Details concerning the seasonal changes to the Alboran Sea gyres have been added.

Reviewer comment: Concerning the benthic foraminifera faunal assemblages in section 3.5, I was wondering whether you checked the 63-150 $\mu \mathrm{m}$ fraction? By doing so, you could (qualitatively at least) assess if there is a bias on small species (e.g. the opportunistic specie Epistominella exigua)?

Response: The fraction 63-125 $\mu \mathrm{m}$ (we used a $125 \mu \mathrm{m}$ mesh) was not investigated in this study. It was intended to exclude the smaller forms which are more likely to be displaced by bottom currents (e.g. Lutze and Colbourn, 1984) which govern coldwater coral environments. Moreover, the inclusion of the finer fraction would make the data less comparable to other important benthic foraminiferal studies in the area (e.g. Schönfeld, 2002; Milker \& Schmiedl, 2012; Stalder et al., 2015; 2018; Fentimen et al., 2020). However, we do agree that this approach has its drawbacks, noticeably the underestimation of smaller opportunistic species, and we strongly advocate for the investigation of the finer fraction in areas with weaker bottom currents and for the living assemblages. The authors have considered this methodological point in a study of the Moira Mounds - NE Atlantic CWC mounds (Fentimen et al., 2020 Marine Micropal). Taking into account the pros and cons of integrating the finer fraction $(63-125 \mu \mathrm{m})$, we 
decided to only focus on the larger fraction for this precise setting (this approach was also used in a high energy setting by Schönfeld (1997).

Reviewer comment: Also, you did not mention on which literature you based your foraminifera species identifications? This should be added in the material and methods.

Response: The identifications were based on a selection of benthic foraminiferal atlases (thus cross-referencing), essentially: Jones (1994), Murray (2003), Margreth (2010) and Milker and Schmiedl (2012). This has been added to the Material and Methods. A full list of the literature used for identifying foraminifera species (+ the original description of the given species) has been added as Annex 2 (see attached file).

Reviewer comment: I am aware of the difficulties due to the inconstant depositional processes in this area (which is also a problem in this study but I won't insist on it as you dealt with it fairly in the manuscript), but did you estimate the accumulation rates of benthic foraminifera (BFAR), and compared it to the foraminiferal density and TOC?

Response: We did estimate the BFAR (see attached Annex 1 and Supp. Figure 1) but decided to not include it in the manuscript. We decided to avoid using the BFAR since in such environments, which show intermittent sedimentation and erosive events, we believe it to be an untrustworthy proxy (see response to reviewer 1).

Reviewer comment: It would be very helpful to add pictures of the benthic foraminifera cited in the text, especially those selected for any geochemical measurements. Providing pictures should be generalized in the literature as confusions persist.

Response: We agree with the Reviewer that adding a plate with the most abundant foraminifera species would avoid potential confusions and allow comparison to other studies (and identifications, since these may indeed vary slightly from one person to another). Our identifications are in agreement with Jones (1994), Murray (2003), Margreth (2010) and Milker and Schmiedl (2012) (the literature used; see response to the

Interactive comment

Printer-friendly version

Discussion paper 
comment below and the newly added Annex 2), that clearly illustrate these species. For this reason, and since the manuscript is already figure-rich, we had first decided not to add a plate. However we agree that adding a plate is important to document our identifications so this will be done in the revised version.

Reviewer comment: I don't have access to the Annex, but you could add there a reference list to the original description of each foraminifera specie, at least for those cited in the main text.

Response: This has been added in Annex 2 (in the same table as the list of literature used for identifications). Annex 1 (foram counts) has also been attached to the reply as it was previously missing, we apologize for the inconvenience.

Reviewer comment: It is hard to get decisive and conclusive interpretation from the TOC, according to the curve presented in fig. 4. It would be interesting to compare this curve with the BFAR. In any case, the interpretation should be toned down.

Response: We agree with the Reviewer that these interpretations need to be toned down (also in agreement with Reviewer 1's comments). A curve comparing TOC to the BFAR is attached "Fig. BFAR _ TOC"). This can be added as Supp. Material to the manuscript if wished. However, BFAR in cold-water coral environments is biased by bottom current dynamics and may rather reflect hiatuses. Also, as mentioned in the reply to Reviewer 1, a number of micropaleontological studies have pointed out the reasons why the BFAR is potentially biased (see the review Jorissen et al., 2007). Noticeably, Naidu and Malmgren (1995) showed that in low oxygen environments, BFAR does not reflect surface-water productivity. Since we suspect that the seafloor at BR1 was at times depleted in oxygen, we further avoided to use the BFAR as a productivity proxy. Moreover, taphonomic processes, which directly impact BFAR, are not well constrained (see for example Murray, 2006; Stefanoudis et al., 2017; Capotondi et al., 2020; Fentimen et al., 2020).

Reviewer comment: If available, other proxies of primary productivity changes would

Printer-friendly version

Discussion paper 
be appreciable. If the sieved samples are still available, the fastest (but not the best) way to try check this would be to count the planktonic foraminifera and calculate their accumulation rates?

Response: This approach would indeed be the fastest but as mentioned, not the best. Indeed, the accumulation rate of planktonic foraminifera is considerably biased in such settings by the strong currents affecting the area (see also response to comment above). We believe that the accumulation rate of planktonic foraminifera would probably reflect sorting by bottom currents rather than productivity (see for example, Fentimen et al., 2020, Marine Micropal) and as such should be avoided. For this study we had started assessing planktonic foraminiferal assemblages but decided against further investigations for the following reasons: (1) planktonic foraminifera are more likely to be allochtonous than benthic foraminifera, especially considering the setting, and (2) planktonic foraminifera from the study site were concentrated essentially within the smaller sized material $(63-150 \mu \mathrm{m})$, thus further increasing the probability of a high contribution of allochtonous foraminifera.

Reviewer comment: Section 4.3: You only show the section 1 in the figure, will the other sections be added in supplementary? This would be interesting to illustrate your description line 320 .

Response: Other sections will be added to the manuscript (also in agreement with the comment by Reviewer 1 ) together with the CT visualization of fragments bigger than 2 $\mathrm{cm}$. We are currently working on producing this.

Reviewer comment: I agree that $\mathrm{Zr} / \mathrm{Al}$ and $\mathrm{Rb} / \mathrm{Al}$ differ from $\mathrm{Ti} / \mathrm{Al}$ and $\mathrm{Si} / \mathrm{Al}$ but mostly in the fact that the first two are harder to interpret than the later. Unfortunately, I am not sure that any conclusive strong interpretation can be extracted from these curves.

Response: The interpretations linked to the XRF will be toned down, as previously suggested. We aim to use this dataset rather as supporting information for the macrofaunal and microfaunal assemblages. We will make this clearer in the revised version

Interactive comment
Printer-friendly version

Discussion paper 
of the manuscript.

Reviewer comment: In the discussion it would be very helpful to have a figure showing TOC + benthic forams assemblages (at least the species that have a "significant ecological meaning") $+\delta 13 \mathrm{C}$, especially to illustrate the discussion lines $555-560$.

Response: We agree with this, however this was not done to avoid overloading Figure 7 which already contains a lot of information. Thus we would prefer not to combine comment or present a new figure, especially since the manuscript already contains quite some figures (+ the ones that will be added following both reviewers' comments: see reply general comment and reply to reviewer 1$)$.

Reviewer comment: Line 412-413: You only described B. spathulata as opportunistic (line 394), but you used the plural form "taxa". Do you consider all the fresh organic matter-feeding species as opportunistic?

Response: Indeed this is not clearly stated in the sentence, precision is added in the revised version. Indeed, we consider $B$. spathulata as opportunistic but also Bulimina spp., following the observations made by Eichler et al. (2014) or Lutze and Coulbourn (1984).

Reviewer comment: Also, it has been suggested that relatively small shelled species that rely on fresh organic matter show a faster (/stronger?) response to seasonality changes (Fontanier et al., 2006). Are there any signs of E. exigua in the samples?

Response: There was no E. exigua in the samples. There were very scarce occurrences of Alabaminella weddellensis (a species sharing the same ecology, i.e. responding rapidly to periods of increased phytodetritus input). See also attached Annex 1. We agree that $E$. exigua (and other opportunistic phytodetritus-feeding species) are generally small and are essentially found in the smaller fraction (63-125 $\mu \mathrm{m})$, so variations in this species abundance are possibly missed. Other studies at BR 1 did not either report the presence of Epistominella exigua and E. vitrea (Stalder et al., 2015;

Printer-friendly version

Discussion paper 
2018). This question and response go together with the discussion to integrate or not the finer fraction (63 - $125 \mu \mathrm{m}$ ) - see above, previous comment.

Reviewer comment: Since we are in the seasonality topic, are there any past and present evidences of seasonal changes affecting the surface stratification in the area and also the primary productivity? This would be the right place in the article to discuss this topic, and eventually support the benthic foraminifera findings (especially for what is observed at MIS 5 and 7). This addition would be a solution to balance the "'weakness"' of the XRF trends. You could also add a figure showing XRF + benthic forams for the runoff hypothesis.

Response: Primary productivity in the Alboran Sea is controlled by a number of variables: the formation of Western Mediterranean Deep Water in the Gulf of Lions which would itself be influenced by varying atmospheric conditions (for studies on the topic, see for example Ausin et al. (2014; 2015) and references therein). Moreover, the influence of entering Atlantic Water (which enters as a jet at the Strait of Gibraltar) on primary productivity is also important and is subject to seasonal changes (the strength of the jet at the Strait of Gibraltar will have an effect on the strength of both Western and Eastern Alboran Gyres). For literature, see for example: Heburn and La Violette (1990), Oguz et al. (2014). So seasonal changes do indeed affect surface stratification at the study site. However, considering the location of BR 1, the benthic foraminiferal assemblages, TOC (see Van Krevelen diagram attached) and at a lesser extent XRF results, we believe that $B R 1$ is essentially impacted by variations in terrestrial input, and secondly by water mass rearrangements (see discussion section 5.1.2). Again we would prefer to avoid adding an extra figure for the reasons already mentioned above (i.e. high number of figures already presented in the manuscript).

Reviewer comment: Is there any occurrence of deep infaunal and/or dysoxic species such as Globobulimina spp, Chilostomella, etc ?

Response: Deep infaunal species can be considered rare. The most abundant deep

Interactive comment

Printer-friendly version

Discussion paper 
infaunal species is Chilostomella oolina (max. abundance 5\%, av. abundance ca. 1 to $2 \%$ ). Globobulimids are even less abundant (max. abundance $2 \%$, av. abundance approximately $0.5 \%$ ). See Annex 1 (attached). In order to estimate oxygen content variation, we used the formula proposed by Schmiedl et al. (2003): $(\mathrm{OH} /(\mathrm{OH}+\mathrm{LO})$ + Div) ${ }^{*} 0.5$, with $\mathrm{OH}=$ relative abundance of high oxygen indicators (e.g. Cibicides pachyderma, Gyroidina orbicularis, Hanzawaia boueana, Lenticulina spp., Pyrgo spp., Quinqueloculina spp., and Sigmoilopsis schlumbergeri), LO = relative abundance of low oxygen indicators (Bolivina spp., Bulimina spp., Cassidulina carinata, Chilostomella oolina, Globobulimina spp., Melonis barleeanus, Nonionella turgida, Praeglobobulimina ovata, Trifarina spp., and Uvigerina spp.) and Div = normalized benthic foraminifera diversity. We decided however not to include this in the manuscript since it essentially reflects the abundance of buliminids, and was hence redundant.

Reviewer comment: Section 5.1.2 It is very difficult to see systematic interglacial SS increases supporting seafloor turbulence. Also, the abundances of T. angulosa which is often associated with strong bottom water energy do not support this here. The steady fluvial increase during MIS 5 suggested by SS figure 8 might be plausible, but it is still hard to observe a systematic strong glacial/interglacial signal.

Response: We agree with the Reviewer that this statement is misleading and does not match with the the foraminiferal assemblages. The sentence has thus been reworked in the revised version of the manuscript. The sentence now reads: "This would promote the formation of internal waves and would have favoured coral proliferation by increasing lateral food availability (Fig. 10)". This is also in better agreement with the title of the section.

Reviewer comment: The second half of section 5.1.1 is well argumented. But I still have questions about the fate of these runoffs. How can we be sure that this "material" is not displaced laterally by the currents, away from the studied area? Line 621: I am not sure that there is enough arguments in the discussion to dismiss water mass rearrangements yet.

\section{CPD}

Interactive comment
Printer-friendly version

Discussion paper 
Response: The results of the RockEval analyses indicate that the origin of the organic matter preserved in the sediment at Brittlestar Ridge 1 is of terrestrial origin. The newly added figure (Oxygen Index vs. Hydrogen Index diagram, see attached) demonstrates this. If the material resulting from terrestrial run offs were to be displaced laterally by currents, one would expect the signal of the organic matter preserved at BR 1 to be rather marine in origin. This is not the case. The statement Line 621 is not intended to dismiss or exclude water mass rearrangements, it rather suggests that they are of secondary importance at BR 1 when compared to fluvial input. This is especially true in comparison to other CWC environments, for example the extensively studied CWC mounds in the Northeast Atlantic (Irish margin), where water mass rearrangements are believed to drive almost exclusively cold-water coral growth dynamics.

Reviewer comment: Line 646: What about seasonality changes?

Response: No seasonality changes were documented in this study, so we cannot make any conclusions about these (nor can we confirm anything).

Reviewer comment: For the conclusion and also as a conclusive remark for all the manuscript; I suggest toning down the terrestrial inputs implications as the XRF data far from being clear enough to give decisive interpretations. I also suggest keeping the door open to other processes such as water mass reorganization or maybe the impact of primary productivity changes due to seasonality variations (affecting the gyres?).

Response: We agree that the XRF data needs to be toned down (as mentioned previously and in the reply to Reviewer 1). However the conclusion that fluvial input plays a decisive role in coral development is especially based is also and especially supported by benthic foraminiferal assemblages (see section 5.1.1). The influence of water mass rearrangements is also highlighted in the conclusion (e.g. "Increased fluvial organic matter inputs are driven by the increased impact of warm and moist Atlantic air masses with intensified Western and Eastern Alboran Gyres that lead to more important turnover between surface and intermediate water masses. This phenomenon 
is promoted by enhanced Modified Atlantic Water inflow at the Strait of Gibraltar"). We do not exclude in this final section the effect of water mass rearrangements and do not develop the impact of seasonality variations since we have little indications about this in this study. Hence we would prefer to keep the conclusion brief and as such.

Other suggestions

Reviewer comment: Lines 24 - 36 I would suggest a reorganization of the second half of the abstract, as it feels that information are randomly presented, which might confuse some readers.

Response: This has been reworked in the revised version of the manuscript.

Reviewer comment: Line 134 isn't it northwest instead of northeast that the MAW enters the Alboran Sea?

Response: Indeed, this has been corrected.

Reviewer comment: Line 226 I think that it is important to mention in section 3.5 the error on the benthic foraminifera relative percentages. Withấij300 specimens counted, variations of less thanấij5 \% are not very trustworthy. For more statistics of the sorts you can check and cite Patterson and Fishbein, 1989 and Fatela and Taborda, 2002.

Response: This has been mentioned in the latest version of the manuscript.

Reviewer comment: Lines $300-304$ are a bit too interpretative and should be placed and developed in the discussion.

Response: We agree with the Reviewer. This has been placed and further developed in the discussion (in addition to the OI vs. HI diagram which illustrates this statement, see attached figure).

Reviewer comment: Line 309 The sentence "This trend is mirrored in GS (Fig. 4)" is not useful as you are describing both SS and GS starting at line 306. - I think that you could place figure 5 in supplementary information, and put the sentences lines 310- 
313; "The percentage of sortable silt (SS\%) increases with...and SS\% is indicative of a sorting process induced by bottom currents (Fig. 5)", in the discussion, to support your (toned-down) interpretations.

Response: We agree with the Reviewer on both theses points. Figure 5 has been moved to the Annexes (making room for other figures, as stated in the general comment). Reviewer comment: Line 323, is it possible to indicate quantitavely the dominance of $\mathrm{B}$. dichotoma?

Response: Yes this is possible and has been added in the revised version of the manuscript. B. dichotoma makes up for over $95 \%$ of all counted bryozoans.

Reviewer comment: Could sentences lines $327-329$ be simplified by just saying that bryozoan and coral content is generally inversely correlated?

Response: This could be done but we believe that it would possibly be a case of over simplification. Coral and bryozoan content are indeed anti-correlated during MIS 5 and MIS 2 but the distribution pattern of both organisms does not always follow such a pattern (see for example MIS 6).

Reviewer comment: Lines 346onward, it would be helpful to display the mean percentages of each species within the Bulimina grouping. Just out of curiosity, is the offset between the 3 species relatively stable down-core? I would also displace the diversity sentences (lines $343-345$ ) to the end of the 4.4 section.

Response: The mean percentages of Buliminid species can be found in Annex 1. The most abundant species is $B$. marginata, followed by B. striata and then B. aculeatea. $B$. aculeata shows the strongest offset with the two other species (noticeably during the last glacial). Moving lines $343-345$ to end of the section has been done in the revised version of the manuscript.

Reviewer comment: Line 359 I think you meant T. angulosa which is the one showing aấij30 \% abundance during MIS 6. I can't see 30 \% for D. coronata during MIS 4 in

\section{CPD}

Interactive comment
Printer-friendly version

Discussion paper 
figure 7. I advise to recheck the description of this figure in general.

Response: This sentence needs indeed to be corrected. D. coronata reaches ca. 20 CPD $\%$ during MIS 4. Corrections have been made.

Reviewer comment: Section 4.5 The Holocene is not mentioned, yet it is among the periods showing the most changes.

Interactive comment

Response: We rather chose to highlight the changes at the transition between the last glacial and the Holocene: "The passage from MIS 2 to MIS 1 is marked by a sharp decrease in planktonic and benthic $\delta 13 \mathrm{C}$ (from $-1.2 \%$ o to $-2.2 \%$ and from $1.8 \%$ o to 1.0 $\%$ respectively)". We chose not to insist too much on the Holocene in this study as this core is not the best suited to study this time interval at BR 1 (cores studied by Fink et al., 2013; Stalder et al., 2015; 2018 are better examples).

Reviewer comment: Line 398 I would replace "support" by "suggest". As mentioned before it would be better to tone down the interpretation. It is also a good spot in the text to put the origin of the TOC.

Response: We agree with the Reviewer. This needs to be toned down and the origin of the organic matter (OI vs. HI diagram) integrated at this stage of the discussion.

Reviewer comment: Line 428 could you please precise where these inputs occur?

Response: Precision added.

Interactive comment on Clim. Past Discuss., https://doi.org/10.5194/cp-2020-82, 2020. 
CPD

Species list and quantitative data of benthic foraminifera from core MD13-3462G

\begin{tabular}{|c|c|c|c|c|c|c|c|c|c|c|c|c|c|c|c|c|}
\hline Depth $(\mathrm{cm})$ & 2 & 12 & 22 & 32 & 42 & 52 & 62 & 72 & 82 & 92 & 102 & 112 & 122 & 132 & 142 & 152 \\
\hline Sum counts & 582 & 438 & 413 & 620 & 616 & 639 & 434 & 394 & 341 & 374 & 315 & 282 & 301 & 332 & 314 & 341 \\
\hline Split & 16 & 4 & 4 & 2 & 8 & 16 & 4 & 16 & 32 & 16 & 64 & 128 & 64 & 128 & 128 & 64 \\
\hline Total (Sum counts $\times$ Split) & 9312 & 1752 & 1652 & 1240 & 4928 & 10224 & 1736 & 6304 & 10912 & 5984 & 20160 & 36096 & 19264 & 42496 & 40192 & 21824 \\
\hline Fraction weight (g) & 0.8 & 1.07 & 0.86 & 0.32 & 0.76 & 2.39 & 0.62 & 1.69 & 1.46 & 1.01 & 5.01 & 6.47 & 3.04 & 10.85 & 10.38 & 10.32 \\
\hline Foraminifera/g & 11640 & 1637 & 1921 & 3875 & 6484 & 4278 & 2800 & 3730 & 7474 & 5925 & 4024 & 5579 & 6337 & 3917 & 3872 & 2115 \\
\hline Adelosina laevigata & 0 & 0 & 0 & 0 & 0 & 0 & 0 & 0 & 0 & 0 & 0 & 0 & 0 & 0 & 0 & 0 \\
\hline Alabaminella weddellensis & 0 & 0 & 0 & 0 & 0 & 0 & 0 & 0 & 0 & 0 & 0 & 0 & 0 & 0 & 0 & \\
\hline Ammonia beccarii & 0 & 0 & 0 & 0 & 0 & 0 & 0 & 0 & 0 & 0 & 0 & 1 & 0 & 0 & 0 & 0 \\
\hline Amphistegina lessonii & 0 & 0 & 0 & 0 & 0 & 0 & 0 & 0 & 0 & 0 & 0 & 0 & 0 & 0 & 0 & \\
\hline Amphycorina scalaris & 6 & 14 & 8 & 0 & 1 & 0 & 0 & 0 & 0 & 0 & 0 & 1 & 0 & 0 & 0 & \\
\hline Anomalinoides globulosus & 0 & 0 & 0 & 0 & 0 & 0 & 1 & 0 & 0 & 0 & 0 & 1 & 0 & 1 & 1 & 1 \\
\hline Astrononion antarcticus & 0 & 0 & 1 & 2 & 0 & 0 & 0 & 0 & 0 & 0 & 0 & 1 & 0 & 0 & 0 & \\
\hline Astrononion gallowayi & 0 & 0 & 0 & 3 & 0 & 0 & 2 & 0 & 0 & 0 & 0 & 0 & 0 & 0 & 0 & 0 \\
\hline Astrononior & 0 & 0 & 0 & 22 & 0 & 7 & 19 & 29 & 6 & 0 & 17 & 15 & 1 & 2 & 12 & 0 \\
\hline Bigenerina nodosaria & 1 & 3 & 0 & 0 & 0 & 0 & 0 & 0 & 0 & 0 & 1 & 0 & 0 & 0 & 0 & 0 \\
\hline Biloculinella depressa & 0 & 0 & 0 & 0 & 0 & 0 & 0 & 0 & 0 & 0 & 0 & 0 & 0 & 0 & 0 & \\
\hline Biloculinell & 0 & 0 & 0 & 0 & 0 & 0 & 0 & 0 & 0 & 0 & 0 & 0 & 0 & 1 & 0 & 0 \\
\hline Biloculinella labiata & 0 & 1 & 1 & 1 & 0 & 1 & 0 & 0 & 1 & 0 & 0 & 0 & 0 & 0 & 0 & 0 \\
\hline Bolivina alata & 5 & 2 & 2 & 1 & 5 & 2 & 0 & 0 & 0 & 0 & 4 & 0 & 0 & 2 & 3 & 3 \\
\hline Bolivina difformis & 2 & 2 & 1 & 0 & 0 & 0 & 0 & 0 & 0 & 0 & 0 & 0 & 0 & 0 & 0 & 0 \\
\hline Bolivina pseudoplicata & 0 & 0 & 2 & 1 & 3 & 0 & 1 & 2 & 1 & 1 & 3 & 1 & 0 & 0 & 0 & 0 \\
\hline Bolivina spathulata & 1 & 3 & 19 & 0 & 9 & 4 & 4 & 4 & 10 & 37 & 7 & 3 & 4 & 2 & 6 & 6 \\
\hline Bolivina spinescens & 0 & 0 & 1 & 0 & 0 & 0 & 0 & 0 & 0 & 0 & 0 & 0 & 0 & 0 & 0 & 0 \\
\hline Bolivina striatula & 2 & 2 & 3 & 6 & 9 & 11 & 12 & 13 & 3 & 0 & 8 & 2 & 13 & 12 & 5 & 4 \\
\hline Bolivina subspinescens & 0 & 0 & 0 & 0 & 0 & 0 & 0 & 0 & 0 & 0 & 0 & 0 & 0 & 0 & 0 & 0 \\
\hline Bolivina variabilis & 0 & 0 & 0 & 0 & 0 & 0 & 0 & 0 & 0 & 0 & 0 & 0 & 0 & 0 & 0 & 0 \\
\hline Bulimina aculeata & 10 & 5 & 11 & 7 & 8 & 16 & 1 & 4 & 0 & 2 & 3 & 4 & 4 & 7 & 12 & 10 \\
\hline Bulimina marginata & 23 & 44 & 31 & 3 & 5 & 4 & 2 & 2 & 2 & 8 & 3 & 2 & 0 & 2 & 1 & 1 \\
\hline Bulimina striata & 7 & 20 & 27 & 3 & 1 & 0 & 0 & 0 & 0 & 0 & 0 & 0 & 0 & 0 & 0 & 0 \\
\hline Cancris auricula & 0 & 0 & 0 & 0 & 0 & 0 & 0 & 0 & 0 & 0 & 0 & 0 & 0 & 0 & 0 & 0 \\
\hline Cassidulina carinata & 0 & 0 & 0 & 0 & 0 & 0 & 0 & 0 & 0 & 0 & 1 & 0 & 0 & 0 & 0 & 0 \\
\hline Cassidulina crassa & 6 & 18 & 10 & 2 & 22 & 8 & 2 & 2 & 9 & 2 & 3 & 4 & 4 & 8 & 3 & 3 \\
\hline Cassidulina Iaevigata & 52 & 17 & 32 & 96 & 60 & 68 & 45 & 42 & 61 & 20 & 34 & 23 & 48 & 43 & 33 & 66 \\
\hline Cassidulina reniforme & 0 & 3 & 0 & 2 & 4 & 0 & 0 & 4 & 4 & 1 & 0 & 0 & 0 & 0 & 0 & 0 \\
\hline Cassidulinoides bradyi & 2 & 1 & 2 & 0 & 0 & 2 & 0 & 0 & 0 & 0 & 1 & 1 & 0 & 1 & 0 & 0 \\
\hline Chilostomella oolina & 2 & 8 & 6 & 0 & 0 & 0 & 0 & 0 & 0 & 0 & 0 & 0 & 0 & 0 & 0 & 0 \\
\hline Cibicides aravaensis & 3 & 17 & 10 & 1 & 10 & 6 & 1 & 2 & 6 & 2 & 0 & 1 & 0 & 2 & 2 & 0 \\
\hline
\end{tabular}

Interactive
comment

Printer-friendly version

Fig. 1.

Discussion paper 


\section{Interactive \\ comment}

\begin{tabular}{|c|c|c|}
\hline Species & Original name & References used for identification \\
\hline Adelosina laevigata d'Orbigny, 1826 & Adelosina laevigata d'Orbigny, 1826 & Milker and Schmied, 2012 (Fig. 12. 18-19) \\
\hline Alabaminella weddellensis(Earland, 1936) & Eponides weddellensis Earland, 1936 & Erdem and Schönfeld, 2017 (Fig. 8. 24); Setoyama and Kaminski, 2015 (Fig. 5. 3) \\
\hline Ammonia beccarï (Linnaeus, 1758) & Nautilus beccarii Linnaeus, 1758 & Milker and Schmied, 2012 (Fig. 27. 1-2) \\
\hline Amphistegina lessonii d'Orbigny, 1826 & Amphistegina lessonii d'Orbigny, 1826 & Hottinger, 1993 (Pl. 184, Fig. 1-11) \\
\hline Amphicoryna scalaris (Batsch, 1791) & Nautilus scalaris Batsch, 1791 & Murray, 2003 (Fig. 5. 1); Milker and Schmiedl, 2012 (Fig. 18. 22-25) \\
\hline Anomalinoides globulosus (Chapman and Parr, 1937) & Anomalina globulosa Chapman and Parr, 1937 & Margreth, 2010 (Pl. 39, Fig. 1) \\
\hline Astrononion antarcticus Parr, 1950 & Astrononion antarcticus Parr, 1950 & Margreth, 2010 (Pl. 37, Fig. 4) \\
\hline Astrononion gallowayi Loeblich and Tappan, 1953 & Astrononion gallowayi Loeblich and Tappan, 1953 & Margreth, 2010 (P. 37, Fig. 3) \\
\hline Astrononion stelligerum (d'Orbigny, 1839) & Nonionina stelligera d'Orbigny, 1839 & Cimerman and Langer, 1991 (PI. 84, Fig. 13-15) \\
\hline Bigenerina nodosaria d'Orbigny, 1826 & Bigenerina nodosaria d'Orbigny, 1826 & Margreth, 2010 (Pl. 5, Fig. 5); Milker and Schmiedl, 2012 (Fig. 10. 10-11) \\
\hline Biloculinella depressa (d'Orbigny, 1826) & Biloculina depressa d'Orbigny, 1826 & Margreth, 2010 (Pl. 8, Fig. 3); Murray, 2003 (Fig. 4. 2-3) \\
\hline Biloculinella globulus (Bornemann, 1855) & Biloculina globulus Bornemann, 1855 & Margreth, 2010 (Pl. 8, Fig. 2); Milker and Schmied, 2012 (Fig. 16. 19) \\
\hline Biloculinella inflata (Wright, 1902) & Biloculina inflata Wright, 1902 & Milker and Schmiedl, 2012 (Fig. 16. 20) \\
\hline Biloculinella labiata (Schlumberger, 1891) & Biloculina labiata Schlumberger, 1891 & Milker and Schmied, 2012 (Fig. 16. 21-22) \\
\hline Bolivina alata (Seguenza, 1862) & Vulvulina alata Seguenza, 1862 & Margreth, 2010 (PI. 24, Fig. 1) \\
\hline Bolivina difformis (Williamson, 1858) & Textularia variabilis var. difformis Williamson, 1858 & Margreth, 2010 (PI. 24, Fig. 6); Milker and Schmiedl, 2012 (Fig. 19. 28-29) \\
\hline Bolivina pseudoplicata Heron-Allen an Earland, 1930 & Bolivina pseudoplicata Heron-Allen an Earland, 1930 & Milker and Schmied, 2012 (Fig- 19. 22-23); Murray, 2003 (Fig. 5. 17) \\
\hline Bolivina spathulata (Williamson, 1858) & Textularia variabilis var. spathulata Williamson, 1858 & Milker and Schmied, 2012 (Fig. 20. 1-2) \\
\hline Bolivina spinescens Cushman, 1911 & Bolivina spinescens Cushman, 1911 & Margreth, 2010 (Pl. 24, Fig. 7) \\
\hline Bolivina striatula Cushman, 1922 & Bolivina striatula Cushman, 1922 & Margreth, 2010 (Pl. 24, Fig. 5); Milker and Schmiedl, 2012 (Fig. 20. 3) \\
\hline Bolivina subspinescens Cushman, 1922 & Bolivina subspinescens Cushman, 1922 & Margreth, 2010 (Pl. 24, Fig. 8); Milker and Schmiedl, 2012 (Fig. 19. 24) \\
\hline Bolivina variabilis (Williamson, 1858) & Textularia variabilis Williamson, 1858 & Milker and Schmied, 2012 (Fig. 19. 25-26) \\
\hline Bulimina aculeata d'Orbigny, 1826 & Bulimina aculeata d'Orbigny, 1826 & Margreth, 2010 (Pl. 27, Fig. 8); Milker and Schmiedl, 2012 (Fig. 20. 19) \\
\hline Bulimina marginata d'Orbigny, 1826 & Bulimina marginata d'Orbigny, 1826 & Milker and Schmied, 2012 (Fig. 20. 23); Murray, 2003 (Fig. 6. 4-5) \\
\hline Bulimina striata d'Orbigny, 1826 & Bulimina striata d'Orbigny, 1826 & Frontalini et al., 2014 (Fig. 6. 5); Margreth, 2010 (P. 27, Fig. 10) \\
\hline Cancris auricula (Fichtel and Moll, 1798) & Nautilus auricula Fichtel and Moll, 1798 & Milker and Schmiedl, 2012 (Fig. 21. 14-15); Murray, 2003 (Fig. 6. 6-7) \\
\hline Cassidulina carinata (Silvestri, 1896) & Cassidulina Iaevigata var. carinata Silvestri, 1896 & Margreth, 2010 (Pl. 25, Fig. 5); Milker and Schmiedl, 2012 (Fig. 20. 5) \\
\hline Cassidulina crassa d'Orbigny, 1839 & Cassidulina crassa d'Orbigny, 1839 & Jones, 1994 (Pl. 54, Fig. 4); Margreth, 2010 (Pl. 26, Fig. 3) \\
\hline Cassidulina laevigata d'Orbigny, 1826 & Cassidulina laevigata d'Orbigny, 1826 & Margreth, 2010 (P. 25, Fig. 4); Murray, 2003 (Fig. 6. 8-10) \\
\hline
\end{tabular}

Fig. 2. 
CPD

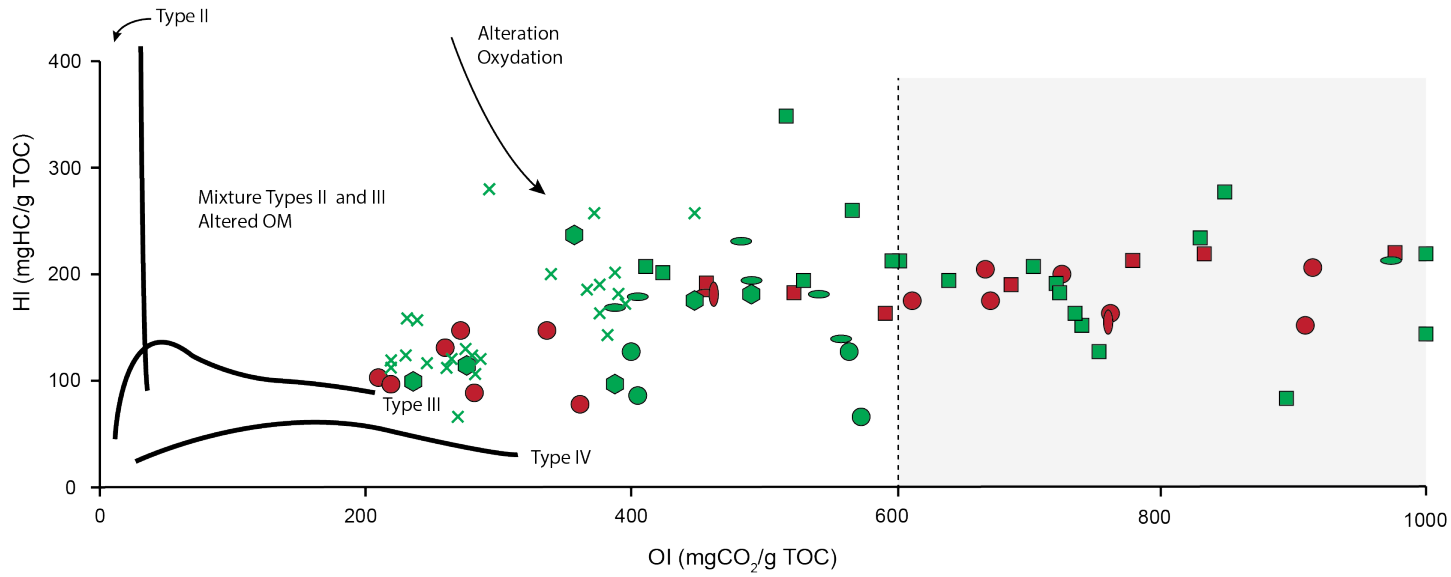

Interactive

comment

Origin of Organic matter

Type II: algal/bacterial

Types III and IV: terrestrial and or reworked

MIS $1 \bigcirc$ MIS 5 MIS 7 MIS 9

0 MIS $2 \times$ MIS $3 \quad$ MIS 4 MIS6

Fig. 3.

Printer-friendly version

Discussion paper 


\section{CPD}

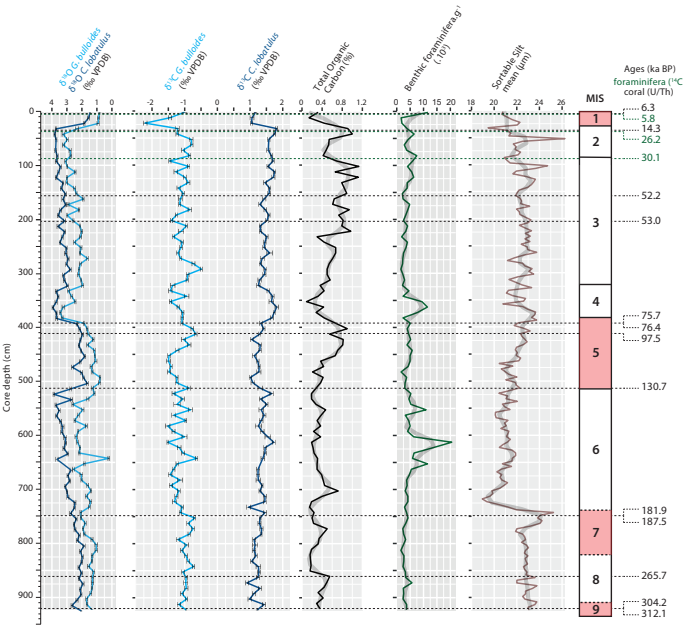

Interactive comment

Fig. 4. 